\title{
DETERMINATION OF KAOLINITE AND HALLOYSITE CRYSTALLITE SIZE WITH X-RAY DIFFRACTION: IMPLICATIONS FOR INDUSTRIAL APPLICATIONS.
}

\section{G. CHRISTIDIS ${ }^{1}$ AND P. MAKRI ${ }^{1}$}

\begin{abstract}
Mean thickness and thickness distribution of kaolinite and halloysite clay fractions was obtained by X-ray diffraction, using the Bertaut-Warren-Averbach (BWA) technique, which determines the coherent scattering domain (CSD). Mean thickness of kaolinite and halloysite was $11.8 \mathrm{~nm}$ and $10.6 \mathrm{~nm}$ respectively and both minerals are characterized by lognormal thickness distribution. Laser scattering, which is often used by the industry, yielded considerably greater mean grain size and bimodal size distribution for both materials due to particle agglomeration. Agglomeration affects optical properties of mineral powders such as brightness adversely, because of light diffusion. A greater discrepancy in particle size determined by the two techniques might explain lower brightness observed in white powders.
\end{abstract}

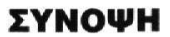

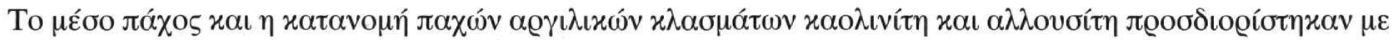

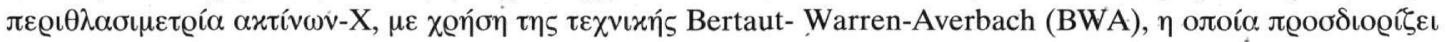

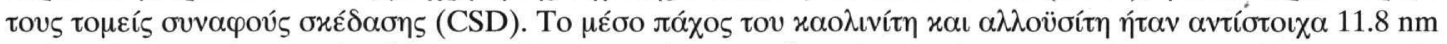

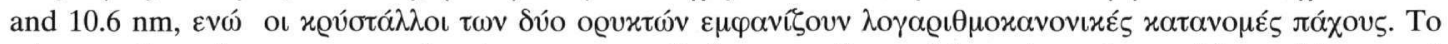
$\mu \varepsilon ́ \sigma o ~ \mu \varepsilon \gamma \varepsilon \varepsilon$

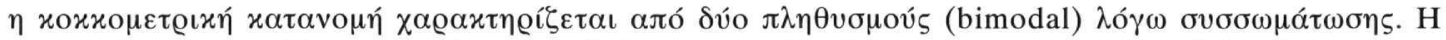

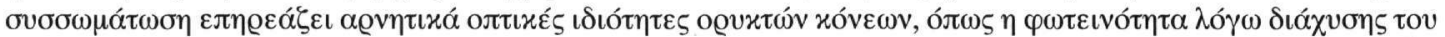

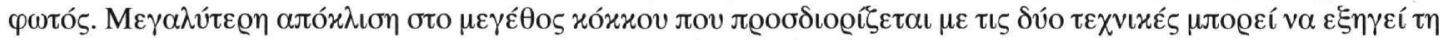

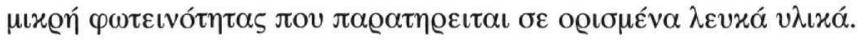

KEY WORDS: X-ray diffraction, coherent scattering domain, BWA technique, particle thickness, thickness distribution, kaolinite, halloysite, laser scattering, agglomeration.

\section{INTRODUCTION}

Particle size of minerals affects significantly their physical and chemical properties such as rheology, specific surface area, cation exchange capacity etc. and its determination might yield geological information about the paleo-environment of formation. In general, crystals, with size approaching nanometer scale are observed with electron microscope and/or atomic force microscope. However both techniques are expensive and time consuming and a researcher can measure only a limited number of grains per sample (Eberl et al. 1996). Measurement of a population of crystals with a reasonable size requires several days of work and might yield a precise average crystallite size but not a precise size distribution. Laser beam diffraction is an alternative method for measuring average grain size. However, the values obtained do not refer to a specific crystallographic direction, the grains measured might belong to different minerals and finally they might result from agglomeration of isolated crystals.

$\mathrm{X}$-ray diffraction (XRD) is a popular technique used in mineralogy, which can assist in this direction. With XRD the sample is scanned with $\mathrm{x}$-rays and the diffracted beam results from millions of separate crystals, with some nanometers size. The method is based on the observation that reflections broaden with decrease of crystallite size. This allows measurement of mean crystallite size of periodical crystals with size 2-100 nm. The size determined with XRD is that of isolated crystals and does not result from crystal agglomeration. Most important, with suitable sample preparation the crystallite size along a certain direction can be obtained. A possible disadvantage of the method is that the crystallite size measured is that of the coherent scattering domain (CSD), which might be smaller than the true crystallite size. Therefore it is necessary to compare measurements from

1. Technical University of Crete, Department of Mineral Resources Engineering, 73100 Chania. 
XRD with other techniques like transmission electron microscopy (TEM).

Kaolinite and halloysite are important industrial minerals utilized in various applications such as fillers and coatings in paper, fillers in plastics, paints and rubber, in ceramics etc (Murray 1999). In these applications grain size of the mineral product is of vital importance and has to meet strict specifications. The purpose of this contribution is a) to measure the crystallite size of well-known kaolins utilized by the industry by XRD and to compare it with laser scattering, which is very popular in mineral industries and b) to draw conclusions about possible influence in industrial applications.

\section{THEORETICAL CONSIDERATIONS}

The method used is based on a well-established technique proposed by Bertaut Warren and Averbach (Eberl et al. 1996), which is known as the BWA technique. This technique analyzes the profiles of XRD peaks and allows calculation of the average thickness of the coherent scattering domains (CSDs), of the particle size distribution and determination of variation of the CDSs due to microstrains. A useful approach to apply the BWA technique in clay minerals is the computer program MUDMASTER (Drits et al. 1998), which has been used recently to study illite, mixed-layer illite-smectite (Drits et al. 1997, 1998, Kotarba \& Srodon, 2000), kaolinite (Elzea et al. 1999) and smectites (Mystkowski et al. 2000, Christidis et al. 2001). The thoretical presentation shown bellow follows Klug and Alexander, 1974, Eberl et al. 1996, and Drits et al. 1998.

MUDMASTER uses the fact that distribution of intensity $I(2 \theta)$ for a peak of a phyllosilicate, which consists of a number of CSDs with strict periodicity along $\mathrm{c}^{*}$-axis is described by the following equation:

$$
\mathrm{I}(2 \theta)=\mathrm{Lp}(2 \theta)^{*} \mathrm{G} 2(2 \theta)^{*} \varphi(2 \theta)
$$

where $\operatorname{Lp}(2 \theta)$ is the Lorentz-polarization factor, $\mathrm{G} 2(2 \theta)$ is the structure factor and $\varphi(2 \theta)$ is the interference function. The values of $\mathrm{Lp}(2 \theta)$ and $\mathrm{G} 2(2 \theta)$ can be calculated a priori if the experimental conditions regarding diffraction and the chemical and physical data for the mineral in question are know (which in fact this is the case). Therefore interference function is given by the equation:

$$
\varphi(2 \theta)=\mathrm{I}(2 \theta) / \mathrm{Lp}(2 \theta) * \mathrm{G} 2(2 \theta)
$$

In fact the interference function describes the influence of phase differences during $x$-ray scattering by each pair of layers separated by $n$ spacings of $d(001)$ in the CDSs, where $n$ is integer, and can be expressed mathematically as a Fourier series. Fourier coefficients $\mathrm{H}(\mathrm{n})$ are obtained by the inverse Fourier transform:

$$
H(n)=\sum_{s^{*}=-1 / 2}^{1 / 2} \varphi\left(\mathrm{s}^{*}\right) \cos 2 \pi \mathrm{ns} *
$$

where $s^{*}$ is a variable. Mean thickness and thickness distribution of the crystals are calculated from the first and second derivative respectively of the Fourier coefficients $\mathrm{H}(\mathrm{n})$, with respect to $\mathrm{n}$ :

$$
\left.\frac{\partial H(n)}{\partial n}\right|_{n \rightarrow 0}=\frac{1}{\bar{M}} \quad \text { (4) and }\left.\quad \frac{\partial^{2} H(n)}{\partial n^{2}}\right|_{n \rightarrow 0}=\frac{f(\mathbf{M})}{\bar{M}}
$$

where $\mathrm{M}$ is the mean thickness and $f(M)$ is thickness distribution.

\section{MATERIALS AND METHODS}

The materials used in this study are a well-crystallized kaolinite from St. Austell, Cornwall, U.K. and a halloysite from Maungapaperua, New Zealand. Kaolinite has formed by a combination of hydrothermal alteration and weathering of the two-mica granite of St. Austell with low-Fe (Bristow, 1993). The amount of kaolinite does not exceed $10-20 \%$ of the altered granite. Halloysite formed from hydrothermal alteration of rhyolitic lava domes and constitutes about $50 \%$ of the altered rock, the remaining $50 \%$ consisting of quartz, amorphous $\mathrm{SiO}_{2}$, opal-CT and plagioclase (Harvey \& Murray, 1993). Except for ceramics, both materials are used as fillers in paper, paints rubber and plastics and the kaolin also as coating in paper (Bristow, 1993, Murray \& Keller 1993).

The raw materials were gently broken with pestle and mortar, soaked in water in the presence of $\mathrm{Na}$ polymetaphosphate deflocculant and were subsequently dispersed with an ultrasonic probe for 20 seconds. The less than $2 \mu \mathrm{m}$ (clay) fraction was separated with sedimentation, spread on glass slides and allowed to dry in atmospheric conditions. The orientated specimens were X-rayed with a Siemens D500 XRD operating at $35 \mathrm{kV}$ 
and 40Ma, using $\mathrm{CuK} \alpha$ radiation and a graphite monochromator. The scanning step used was 0.02 and the counting time per step was 3 seconds. The use of appropriately thick samples $\left(3 \mathrm{mg} / \mathrm{cm}^{2}\right)$ counterbalances a possible background increase due to the use of glass slides. The raw data were transformed to Microsoft Excel format and loaded to MUDMASTER. Determination of mean thickness and thickness distribution was carried out using the 001 peak for both minerals.

For terms of comparison the particle size distribution (PSD) of the clay fraction of both minerals previously dispersed in distilled water was also measured by laser scattering (Malvern Laser Analyzer). The instrument had a He-Ne laser source $(\lambda=0.63 \mu \mathrm{m})$. The particle size measured is equivalent to the diameter of a sphere with volume equal to that of the particle.

\section{RESULTS}

The X-ray traces of the orientated samples are shown in Figure 1. Kaolinite clay fraction is free of admixtures, while the halloysite clay fraction contains small amounts of opal-CT. Halloysite crystals belong to the 7 ? variety, since the $\mathrm{d}(001)$ spacing is 7.4 ?. In both materials the 001 peak is not affected by other admixtures or mixed-layering with other clay minerals. Therefore the BWA analysis of the 001 peak refers exclusively to the mineral in question.

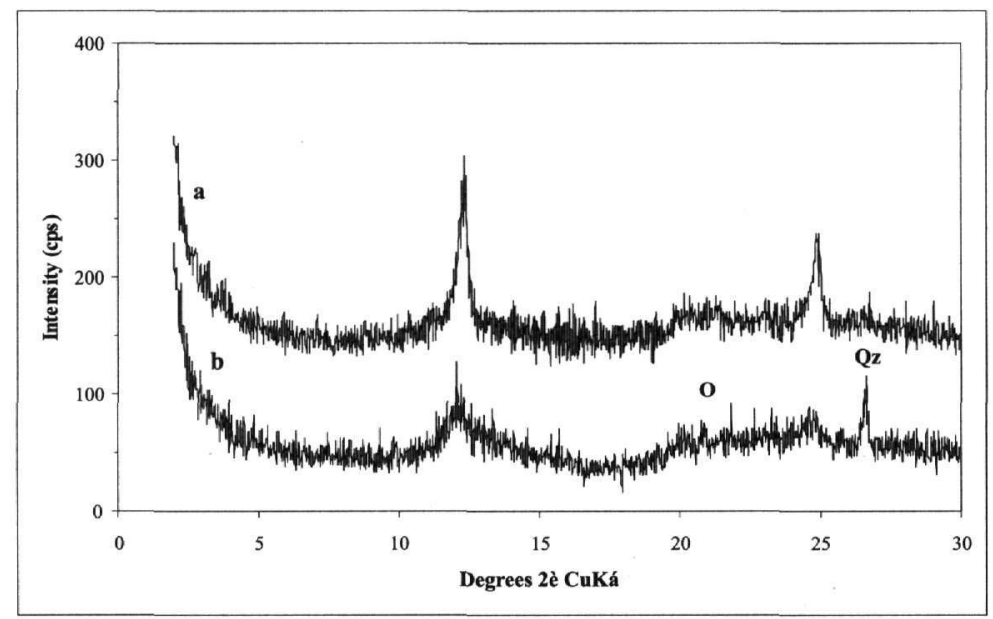

Figure 1. X-ray traces of orientated clay fractions of a) kaolinite and b) halloysite. $O=$ opal-CT, $Q z=q u a r t z$.

The results from BWA analysis for kaolinite are shown in Table 1 and Figure 2a. The mean thickness of kaolinite CSD is $11.8 \mathrm{~nm}$ (118 ?). This value is about half that reported by Elzea et al. (1999) for a Georgia kaolinite (USA), using the same technique. Since a single kaolinite layer is $0.72 \mathrm{~nm}$ thick (7.2 ?), it follows that the mean CSD of the kaolinite studied consists of 16.4 layers i.e. the CSD is a composite unit. Moreover, in Figure 2a it is obvious that the kaolinite thickness distribution is lognormal, because the experimental points fit very well to the simulation curve constructed by MUDMASTER. The lognormal curve was drawn using parameters $\alpha$ (mean of the logarithms of the thicknesses) and $\beta^{2}$ (variance of the logarithms of the thicknesses), which were calculated by MUDMASTER during data processing. Parameters $\alpha$ and $\beta^{2}$ have been used to draw conclusions about the mechanism of formation of various types of minerals including mixed-layer illite smectite, garnet, calcite, dolomite (Eberl et al. 1998) and smectite (Christidis 2001). Such an attempt was not made in this study, due to the small number of samples used. 
Table 1

Kaolinite and halloysite particle size determined with BWA technique and laser scattering. The values of $\alpha$ and $\beta^{2}$ (mean and variance of the logarithms of the observations respectively) are also quoted.

\begin{tabular}{lcccc}
\hline Sample & $\begin{array}{c}\text { Mean thickness } \\
(\mathrm{nm})\end{array}$ & $\alpha$ & $\beta^{2}$ & $\begin{array}{c}\text { Particle size } \\
\text { (im) }\end{array}$ \\
& BWA technique & & & Laser scattering \\
\hline kaolinite & 11.8 & 2.39 & 0.16 & 8.45 \\
halloysite & 7.7 & 1.84 & 0.36 & 1.27 \\
\hline
\end{tabular}
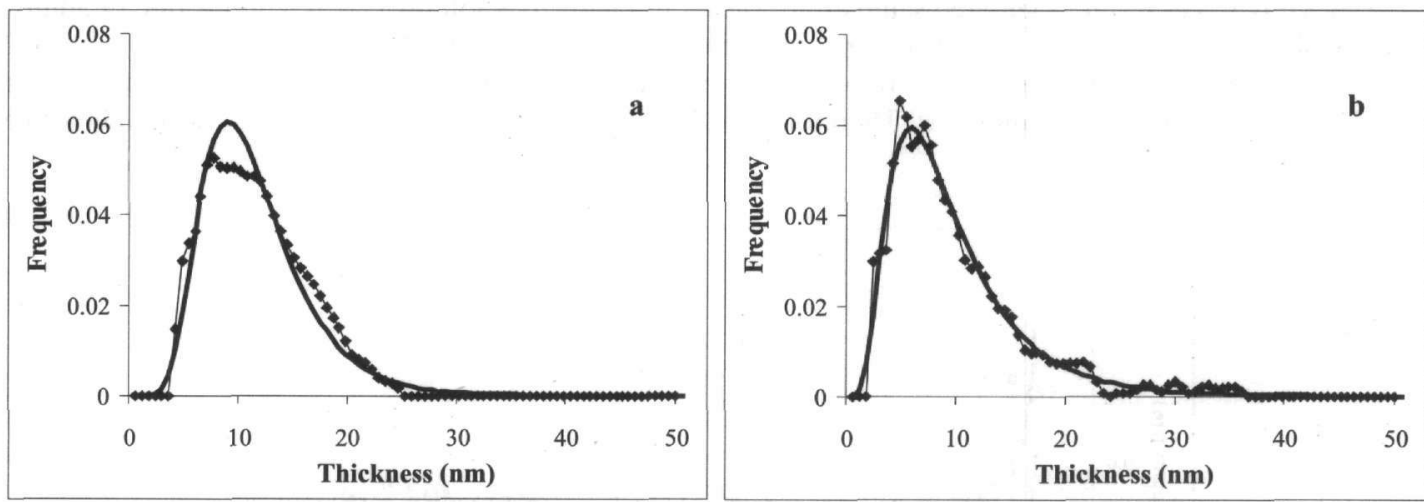

Figure 2. Particle thickness distribution of a) kaolinite and b) halloysite, determined by the BWA technique, using MUDMASTER.

The results from BWA analysis for halloysite are given in Table 1 and Figure $2 \mathrm{~b}$. It is observed that the mean thickness of halloysite CSD is $7.7 \mathrm{~nm}$ (106?), i.e it is smaller than kaolinite. Since a single halloysite layer is 0.74 $\mathrm{nm}$ thick (7.4 ?), it follows that the mean CSD of kaolinite studied consists of 10.4 layers. The smaller thickness of halloysite particles is compatible with the observed peak broadening (Figure 1b). Also, the small crystallite size of both minerals suggests that the influence of instrumental broadening is not significant (Eberl et al. 1996, Christidis unpublished data). Similar to kaolinite, halloysite thickness distribution is lognormal, because the experimental data fit very well to the lognormal curve obtained from MUDMASTER, using parameters $\alpha$ and $\beta^{2}$. Comparing the two lognormal thickness distributions it follows that although parameter $\alpha$ is greater in kaolinite as expected, parameter $\beta^{2}$ is significantly smaller (Table 1 ). This indicates that kaolinite displays a narrower overall thickness distribution compared to halloysite.

The particle size distribution curves and the related frequency histograms obtained by laser scattering are shown in Figure 3. Compared to the results obtained by the BWA technique there are two main differences: a) for both minerals mean particle size with laser scattering is several orders of magnitude greater and b) the particle size distribution displays a bimodal distribution for both minerals. It is interesting that although for both kaolinite and halloysite only clay fractions were analyzed, in the case of kaolinite mean particle size is significantly greater than $2 \mu \mathrm{m}$. Although the magnitude measured by the two methods is not directly comparable, the size separation with free settling in a water column should have yield particle sizes smaller than $2 \mu \mathrm{m}$. The reason for this difference is addressed in the following section. 

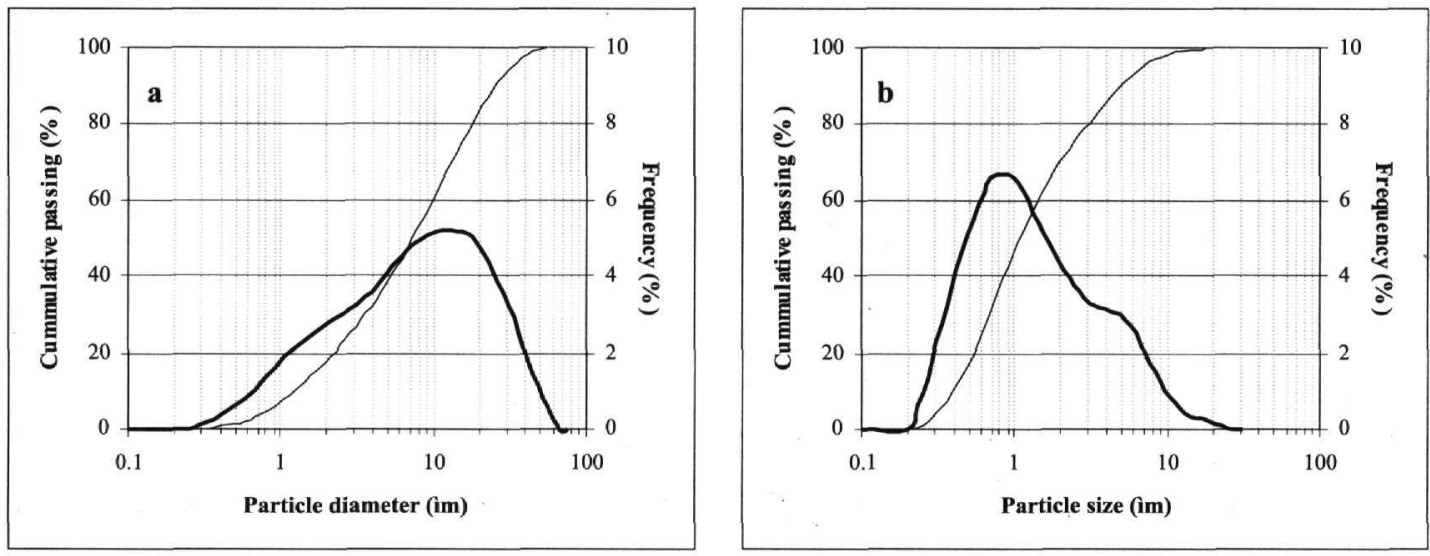

Figure 3. Cummulative grain size distributions and histogram outlines (thick line) of a) kaolinite and b) halloysite clay suspensions determined by laser scattering.

\section{DISCUSSION}

Application of two independent techniques, XRD and laser scattering, for determination of particle size of a kaolinite and a halloysite sample, broadly used by the industry, yielded different results. This difference is partly explained by the fact that the two techniques measure different parameters: BWA determines CSD thickness parallel to $c^{*}$-axis while laser scattering is supposed to measure equivalent volume of spherical particles having various orientations relative to the laser beam. However, in this case even if single clay particles were orientated vertical to the laser beam, the particle size should have been considerably lower, because the size fraction analyzed was smaller than $2 \mu \mathrm{m}$. This is especially true for the kaolinite sample. Moreover the laser scattering data is characterized by a bimodal particle size distribution, which is not observed in the BWA analysis.

These observations suggest that laser scattering results are affected by particle agglomeration, which occurs in the aqueous suspensions. Agglomeration is caused by flocculation of the clay particles. Edge-to-face flocculation (card house effect) is a common phenomenon in kaolinite-water systems (Van Olphen, 1977). In this context the second population having greater size in the bimodal distributions (Fig. 3) reflect agglomeration of kaolinite and halloysite particles. Considering that the CSD is considerably lower and that kaolinite crystallites contain about 14 kaolinite layers on average, it is suggested that kaolinite flocculation involves agglomeration of CSDs, not single layers. This is because a CSD behaves as a fundamental crystallite unit, which however should not be confused with the fundamental particle according to the terminology of Nadaeu et al. (1984). This fundamental crystallite unit is not expected to break up to its elementary layers when dispersed in an aqueous suspension because the clay suspensions prepared for orientated XRD samples are concentrated (2-3 $\mathrm{mg}$ of clay $\left./ \mathrm{cm}^{2}\right)$. In other words these agglomerated particles are also expected to settle on the glass slides used for XRD measurements, but the BWA technique is capable of distinguishing the individual crystallite units.

Determination of PSD of a mineral powder used as filler and particularly coating is of particular importance for industry (Pickering \& Murray, 1994) and laser scattering is a very valuable technique used for that purpose. The results presented in this study indicate that kaolin grains (both kaolinite and halloysite) consist of agglomerated fundamental crystallite units. Particle agglomeration is expected to affect colour properties like brightness adversely, because light diffusion among agglomerated particles is enhanced. Brightness is of primary importance for mineral fillers and coatings. A greater discrepancy between the results obtained by the two techniques is expected to be associated with lower brightness, because light diffusion on the clay surface will be greater. This is because the larger grains measured by laser scattering will consist of a greater number of CSDs which is the basic unit for each mineral and therefore will enhance light diffusion. Therefore it is suggested that application of both techniques will help to interprete optical properties of mineral powders. However the results should be complemented by other techniques like transmission electron microscope (cf. Elzea et al. 1999).

\section{CONCLUSIONS}

The BWA technique is a useful analytical method, which can be applied to determine the thickness of funda- 
mental crystallite units (coherent scattering domains) of various industrial clay minerals. It has been utilized in applied clay mineralogy recently and can be used in association with other techniques, such as laser scattering or/and transmission electron microscopy. The data obtained might be useful to explain variations of important optical properties of industrial fillers and coatings. However, since particle size distribution and thickness are affected by factors like sample preparation, particle agglomeration and type of exchangeable cation present, care should be taken to have consistent methods of sample preparation.

\section{ACKNOWLEDGEMENTS}

The constructive comments of Prof. E. Mposkos and an anonymous referre improved the text.

\section{REFERENCES}

BRISTOW, C.C. (1993) The genesis of the China clays of south-west England-A multistage story. In: (H.H. Murray, W. Bundy \& C. Harvey eds) Kaolin genesis and utilization. Pp 171-203.

CHRISTIDIS, G. (2001) Mechanism of formation and growth of smectites in bentonites: a case study from Kimolos Island, Aegean, Greece. Clays Clay Miner. (in press)

CHRISTIDIS G., MAKRI, P. \& EBERL, D.D. (2001) Thickness of montmorillonite particles saturated with Ca, $\mathrm{Na}$ and $\mathrm{K}$ cations. (Submitted to $12^{\text {th }}$ Inter. Clay Confer. Argentina).

DRITS, V.A., SRODON J. \& EBERL, D.D. (1997) XRD measurement of mean crystalite thickness of illite and illite/smectite:reappraisal of the Kübler index and the Sherrer equation. Clays Clay Miner. 45, 461-475.

DRITS, V.A., EBERL, D.D. \& SRODON J. (1998) XRD measurement of mean thickness, thickness distribution and strain for illite and illite-smectite crystallites. Clays Clay Miner. 46, 38-40.

EBERL, D.D., DRITS, V.A., SRODON, J. \& NüSCH, R. (1996) Mudmaster: A program for calculating crystallite size distributions and strain from the shapes of X-ray diffraction peaks. USGS, Boulder, Co. 56 p.

ELZEA, J., EBERL. D.D. \& RICE (1999) A comparison of kaolinite crystal thickness measurements by XRD, laser diffraction and TEM. Euroclay '99, Krakow, Program with Abstracts, 81.

HARVEY, C. \& MURRAY H.H. (1993) The geology, mineralogy and exploitation halloysite clays of Northland, New Zealand. In: (H.H. Murray, W. Bundy \& C. Harvey eds) Kaolin genesis and utilization. Pp 233-248

KLUG, H.P. \& ALEXANDER, L.E. (1974) X-ray diffraction procedures; $2^{\text {nd }}$ ed. Wiley- Interscience, New York. $966 \mathrm{p}$.

KOTARBA, M. \& SRODON J. (2000) Diagenetic evolution of crystallite thickness distribution of illitic material in Carpathian shales, studied by the Bertaut-Warren-Averbach XRD method (Mudmaster computer program). Clay Miner. 35, 383-391.

MURRAY, H.H. (1999) Applied clay mineralogy today and tomorrow Clay Miner. 34, 39-49.

MURRAY, H.H. \& KELLER W.D. (1993) Kaolins, kaolins and kaolins In: (H.H. Murray, W. Bundy \& C. Harvey eds) Kaolin genesis and utilization. Pp 1-24.

MYSTKOWSKI, K. SRODON, J. \& ELSASS, F (2000) Mean thickness and distribution of smectite crystallites. Clay Miner. 35, 545-447.

NADEAU, P.H., WILSON, M.J., MCHARDY, W.J. \& TAIT, J.M. (1984) Interstratified clays as fundamental particles. Science, 225, 923-925.

VAN OLPHEN H. (1977) An introduction to clay colloid chemistry. Wiley-Interscience, New York, 318 p.

PICKERING S.M. \& MURRAY H.H. (1994) Kaolin. In: (D.D. Carr ed) Industrial Minerals and Rocks $6^{\text {th }}$ ed. AIME. Pp 277-293. 